\title{
Gender differences in prevalence and associations for use of CAM in a large population study
}

\author{
Agnete E Kristoffersen ${ }^{1 *}$, Trine Stub ${ }^{1}$, Anita Salamonsen ${ }^{1}$, Frauke Musial ${ }^{1}$ and Katarina Hamberg ${ }^{2,3}$
}

\begin{abstract}
Background: Self-reported use of Complementary and Alternative Medicine (CAM) varies widely from 10\% to 75\% in the general populations worldwide. When limited to use of a CAM provider $2 \%$ to $49 \%$ reported use is found. CAM use is believed to be closely associated with socio demographic variables such as gender, age, education, income and health complaints. However, studies have only occasionally differentiated CAM use according to gender. Therefore, the aim of the study presented here is to describe the prevalence of CAM use on the background of gender and to describe the specific characteristics of male and female users in the total Tromsø 6 population.

Methods: A total of 12,982 men and women aged 30-87 in the municipality of Troms $\varnothing$, Norway went through a health screening program and completed two self-administered questionnaires in 2007/2008. The questionnaires were developed specifically for the Tromsø study and included questions about life style and health issues in addition to socio demographic variables.

Results: A total of 33\% of the participants reported use of any CAM within the last 12 months, women more often than men ( $42 \%$ and $24 \%$, respectively). When limited to visits to a CAM provider, we found $17 \%$ use among women and $8 \%$ among men. The relationship between the demographic variables and being a CAM user differed significantly between men and women with regard to age, household income, and marital status. We did not find significant differences between men and women concerning education and self-reported health.

Conclusions: Findings from this study suggest that the prevalence and associations for use of CAM differ between men and women concerning several socio demographic variables (age, education and household income). Neglect of women's health care needs in public health care may contribute to the fact that women to a higher degree than men turn to CAM and CAM products.
\end{abstract}

Keywords: CAM use, Norway, Gender differences, Population study, Prevalence

\section{Background}

The use of Complementary and Alternative Medicine (CAM), including a range of different therapeutic modalities such as homeopathy, acupuncture and hands on healing, has for many years increased significantly in the Scandinavian countries [1] and elsewhere [2] but seems to have been stabilized in recent years [3,4]. Self-reported use of any CAM in the general population varies from $10 \%$ to $75 \%$ worldwide. When restricted to visiting a CAM provider, the prevalence of use fluctuates between $2 \%$ and $49 \%$

\footnotetext{
* Correspondence: agnete.kristoffersen@uit.no

${ }^{1}$ The National Research Center in Complementary and Alternative Medicine (NAFKAM), Department of Community Medicine, Faculty of Health Sciences, UiT The Arctic University of Norway, Tromsø, Norway

Full list of author information is available at the end of the article
}

$[5,6]$. These large variations in reported use are mainly due to differences in the definition of a CAM user [7].

In $200816 \%$ of the Norwegian population had visited a CAM provider during the past 12 months, $22 \%$ of these were women and $9 \%$ were men [8]. In 2012 CAM was received within or outside the public health care by $36.6 \%$ of Norwegians. When use of CAM self-help techniques and CAM over the counter (OTC) products were added, $53.6 \%$ of the women and $36.5 \%$ of the men reported such use [3].

In Norway regional cohort studies have been conducted in Nord-Trøndelag (HUNT) and in Tromsø (The Tromsø Cohort study, T1-T6). In the HUNT study, visits to a CAM provider have been studied twice, in 1997 and in 2008. In 1997 a total of $9 \%$ of the respondents reported to 
have visited a CAM provider during the last 12 months. The proportion was 13\% in 2008 [9]. In the Tromsø study, the use of CAM was investigated in the $3^{\text {rd }}(\mathrm{T} 3), 4^{\text {th }}(\mathrm{T} 4)$, $5^{\text {th }}$ (T5), and $6^{\text {th }}$ (T6) study conducted in $1986 / 87,1994 /$ 95, 2001/02 and 2007/08, respectively. The use of a CAM provider during the last 12 months in the $5^{\text {th }}$ Troms $\varnothing$ study was found to be similar to the results in HUNT (1997) [10].

Based on data from large cross sectional surveys, the use of CAM is believed to be closely associated with socio demographic variables such as gender, age, education, income and health complaints [5]. Issues such as control and participation in treatment, perception of illness, natural treatment, holism and philosophy of life have been found to be related to the use of CAM $[11,12]$.

Over the last decades researchers in the medical field have shown a growing interest in gender and differences between men and women in health, disease and health behaviour $[13,14]$. Research has shown that factors such as different biological processes, conditions in daily life, environmental experiences, risk behaviours and different responses to stressful events may contribute to variation in health and well-being in men and women [13-15]. There is also evidence that women are seldom offered the same treatment as men, even though they suffer the same medical conditions, and there was no medical or clinical reason for the treatment choice. Moreover, studies show that women are less likely than men to receive more advanced diagnostic and therapeutic interventions [16-18]. This phenomenon raises the question of gender bias.

In the field of CAM research there are few studies focusing on gender issues, but studies generally demonstrate that men use CAM to a lesser degree than women. Studies focusing on CAM use often focus on particular patient populations, for example patients with pain or different types of cancer. As a matter of fact, measuring gender differences in CAM use based on a few disorders may be associated with a gender bias because the disorders may have different prevalence with regard to gender. Only large prospective population studies, such as the Tromsø study, have the potential to reveal an unbiased perspective with regard to gender differences of CAM use in the total population. However, this topic has rarely been studied in great population studies. Therefore, the aim of the study presented here is to describe the prevalence and characteristics of male and female users of CAM in the total Tromsø 6 population.

\section{Methods}

A total of 12,982 men and women aged 30-87 in the municipality of Tromsø, Norway went through a health screening program and completed two self-administered questionnaires in 2007/2008.
The Tromsø Study series (1-6) are single-centered prospective, population-based health surveys of the adult inhabitants of the municipality of Tromsø, North Norway [19]. The population of Tromsø reflects the distribution of gender, educational level and average income in Norway overall, but the population is somewhat younger [20]. The design includes repeated population health surveys to which total birth cohorts and random samples are invited. The letter of invitation contained a short questionnaire. Individuals, who attended the survey by undergoing a health screening and answered the first questionnaire, subsequently received a second, more detailed questionnaire that they were asked to complete and return at site or later by mail.

The two questionnaires included questions on the general health status, diseases suffered by the respondent or their family, muscle pain and physical discomfort, food habits, alcohol consumption, smoking habits, physical activity in leisure time, level of education, use of medicine and use of health services including CAM. The questions regarding CAM use were not related to any specific disease condition. The questionnaires have not been validated, however, a Cronbach's alpha test of internal consistency of the questions analyzed in this paper was 0.403 .

The health screening included measuring of height, weight, waist and hip circumference and blood pressure. A blood sample was also taken to measure serum total cholesterol, HDL-cholesterol, triglycerides and glucose.

In Norway a CAM provider is understood as a practitioner providing CAM both as alternative and complementary treatment. A CAM provider offers therapies that are mostly offered outside the public health care service and paid out-of-pocket by the patients themselves when fees are required.

Study participants were classified as "CAM-users" by checking YES for one or more of the following questions:

1. Have you during the last 12 months seen an alternative provider (homeopath, acupuncturist, foot zone therapist, herbal medicine practitioner, laying on of hands practitioner, healer, clairvoyant etc.)?

2. In the last 12 months, have you used herbal or "natural" medicine?

3. In the last 12 months, have you used meditation, yoga, qi gong or Tai Chi as self-treatment?

Accordingly, a participant who checked NO for all the three specific CAM-questions was classified as a non-user. The parenthesis examples in question 1 include examples of both modern CAM modalities and traditional healing as it is practiced in North Norway. Traditional healers are nonprofessional and non-commercial therapists who are closely connected to the local culture and world-views [21,22]. 
CAM use is reported at levels $1-3$ in the The National Research Center in Complementary and Alternative Medicine (NAFKAM) 6 level cumulative model for classifying CAM use [7]. In this model the different levels are included in each other (Table 1).

Informants who had seen a chiropractor were not defined as CAM users in this study as chiropractors are regulated health care personnel in Norway. This also applies to informants who had used cod liver oil, Omega-3 capsules, calcium tablets or ordinary vitamins/mineral supplements as these supplements are commonly used in the Norwegian population.

The data were analyzed using chi-square tests and Anova Table in SPSS Windows (version 19.0, SPSS Inc., Chicago, IL).

The Norwegian Data Protection Authority has been notified about the study, and The Regional Committee for Medical and Health Research Ethics has recommended it. The participants have given their informed, written consent.

\section{Results}

Basic characteristics of the studied participants

The studied population $(\mathrm{n}=11104)$ consisted of 5,877 women (52.9\%) and 5,227 men (47.1\%). The response rate to the study was $65.7 \%$. After exclusion of missing response to the CAM questions, the response rate reached 56\%, 58\% among women and 54.3\% among men Figure 1.

The studied population was a rather healthy and gender balanced population with a median age of 58 . More than $92 \%$ defined themselves as being of Norwegian heritage. The largest majority of the remaining $8 \%$ defined themselves as being of indigenous Sami people and/or Kven, descendants of Finnish immigrants. The largest differences between men and women were with regard to income, partner and visits to a general practitioner (GP) (Table 2).

\section{Gender differences in prevalence of CAM use}

A total of 1,423 participants (13.1\%) had seen a CAM provider at least once within the past year (CAM level 2) of which 535 participants $(4.8 \%)$ had seen the provider more than three times (CAM level 1). A total of $3,730(33.3 \%)$ had seen a CAM provider, used CAM
OTC-products and/or used CAM techniques (CAM level 3) within the past year. Women used CAM significantly more often than men at all levels (Table 1).

\section{Gender related associations for CAM use}

The relationship between the demographic variables and being a CAM user differed significantly between men and women with regard to age (CAM level 3), household income (CAM levels 2 and 3) and marital status (CAM levels $1-3)$. We did not find significant differences between men and women concerning education or selfreported health (Table 3 ).

In the sex-disaggregated analysis, we found that poor health, young or middle age was significantly associated with CAM use at all CAM levels in women. We also found university education to be associated with CAM use at levels 1 and 3 , and that divorced/separated women tended to use more CAM at level 3. We did not find household income to be associated with CAM use at any level among women (Table 4).

Among men we found that poor health was associated with CAM use at all CAM levels while older age, lower income and being a widower was associated with CAM use at CAM level 3 (Table 5).

Common in both men and women was that poor health was associated with CAM use at all levels. At levels 1 and 2, the CAM users tended to be younger compared to the non-user in both men and women, while the oldest group was the most frequent CAM user among men at level 3 (Tables 4 and 5).

While lower income is associated with CAM use at level 3 for men, income was not associated with CAM use at all among women (Tables 4 and 5).

\section{Discussion}

Results from this study indicate that women were generally more likely to use CAM at all levels. For both men and women, poor health was associated with CAM utilization at all levels. Moreover, younger age was associated with the use of CAM at all levels for women. Household income in women and university education in men were not associated with the use of CAM at any level.

Many studies report use of CAM in populations. However, the study population, time frame in use and definition

Table 1 Gender differences in CAM use last 12 months according to NAFKAMS cumulative model for reporting CAM use

\begin{tabular}{|c|c|c|c|c|}
\hline & Total $(n=11104) \%$ & Women $(n=5877) \%$ & Men $(n=5227) \%$ & p-value ${ }^{*}$ \\
\hline CAM 1 (seen a CAM provider more than 3 times) & $(n=535) 4.8 \%$ & $(n=353) 6 \%$ & $(n=182) 3.5 \%$ & $<0.000$ \\
\hline CAM 2 (seen a CAM provider at least once) & $(n=1423) 13.1 \%$ & $(n=995) 17.4 \%$ & $(n=428) 8.3 \%$ & $<0.000$ \\
\hline CAM 3 (seen a CAM provider, used OTC products or CAM techniques) & $(n=3730) 33.3 \%$ & $(n=2471) 42.0 \%$ & $(n=1259) 24.1 \%$ & $<0.000$ \\
\hline
\end{tabular}




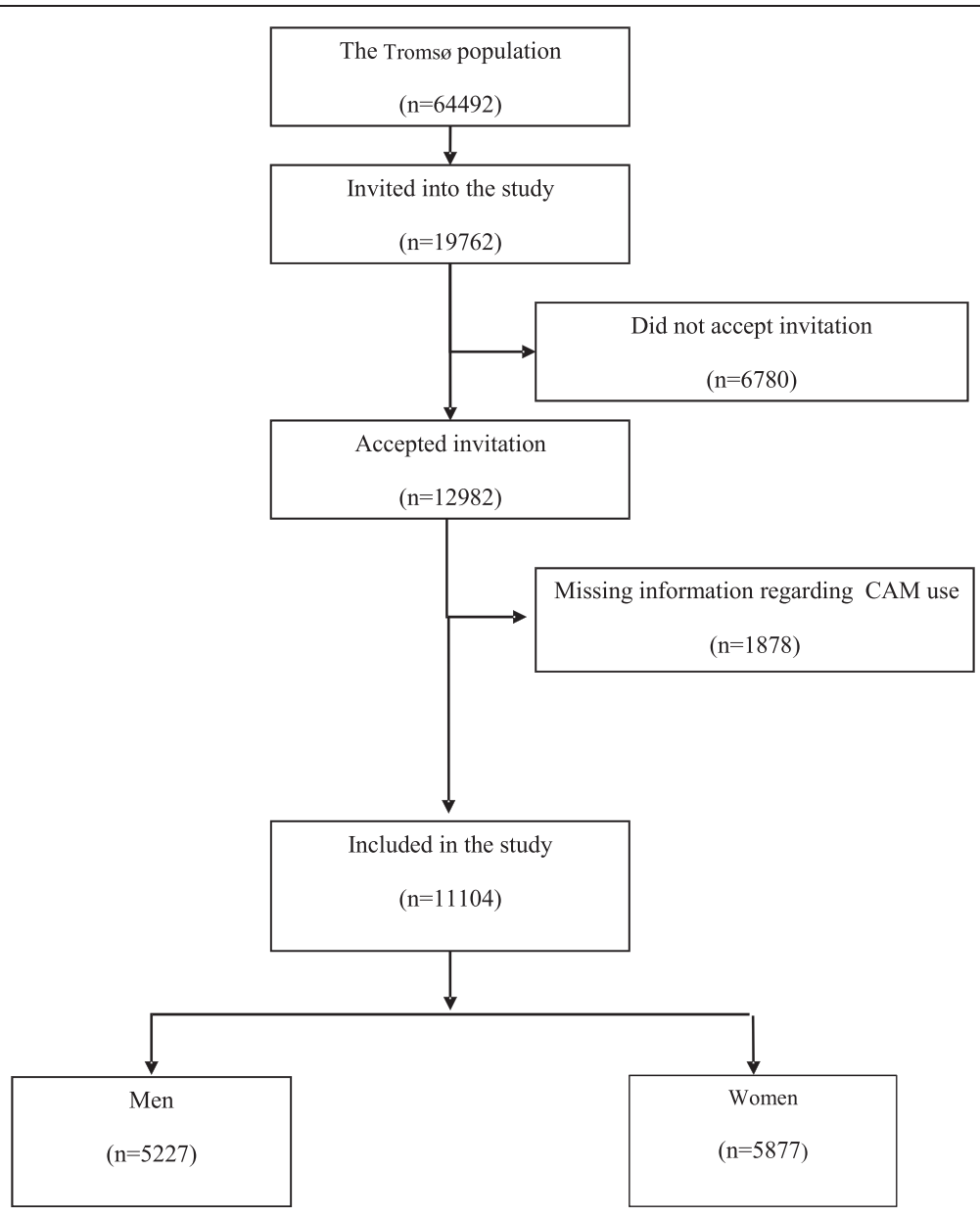

Figure 1 Flow chart that shows the selection of the studied population.

Table 2 Basic characteristics of the studied participants

\begin{tabular}{|c|c|c|c|c|}
\hline & Total $(n=11104)$ & Women $(n=8577)$ & Men $(n=5227)$ & $\mathrm{p}$-value \\
\hline Percentage women & 52.9 & & & \\
\hline Mean age & 56.75 & 56.58 & 56.94 & $0.118^{2}$ \\
\hline Median age (range) & $58(30-87)$ & $58(30-87)$ & $59(30-87)$ & \\
\hline Living with a spouse/partner \% & 75.9 & 69.8 & 82.5 & $<0.000^{1}$ \\
\hline University degree \% & 39.9 & 38.8 & 41 & $<0.000^{1}$ \\
\hline Self-reported good health \% & 67 & 66.2 & 68 & $<0.000^{1}$ \\
\hline Self-reported poor health \% & 5.2 & 5.8 & 4.5 & $<0.000^{1}$ \\
\hline Mean self-reported health $(0-100)$ & 77.5 & 77.1 & 78 & $0.032^{2}$ \\
\hline Median self-reported health $(0-100)$ & 80 & 80 & 80 & \\
\hline $\begin{array}{l}\text { More than } 400000 \text { NOK in household income during } \\
\text { past } 12 \text { months } \%(69000 \$ / 52000 €)\end{array}$ & 62.9 & 56.9 & 69.4 & $<0.000^{1}$ \\
\hline $\begin{array}{l}\text { Less than } 125000 \mathrm{NOK}(21500 \$ / 16400 €) \text { in household } \\
\text { income during past } 12 \text { months } \% \text {. }\end{array}$ & 2.5 & 3.6 & 1.3 & $<0.000^{1}$ \\
\hline Seen a GP during past 12 months \% & 82.2 & 86 & 77.9 & $<0.000^{1}$ \\
\hline
\end{tabular}

${ }^{1}$ Pearson Chi-Square test.

${ }^{2}$ Anova test. 
Table 3 Socio demographic characteristics with comparison between female and male users of CAM

\begin{tabular}{|c|c|c|c|c|c|c|c|c|c|}
\hline & & CAM $1^{1}$ & & & CAM $2^{2}$ & & & CAM $3^{3}$ & \\
\hline & $\begin{array}{c}\text { Women } \\
\%(n)\end{array}$ & $\begin{array}{l}\text { Men } \\
\%(n)\end{array}$ & p-value* & $\begin{array}{c}\text { Women } \\
\%(n)\end{array}$ & $\begin{array}{l}\text { Men } \\
\%(n)\end{array}$ & p-value* & $\begin{array}{c}\text { Women } \\
\%(n)\end{array}$ & $\begin{array}{l}\text { Men } \\
\%(n)\end{array}$ & p-value* \\
\hline Age & & & 0.195 & & & 0.318 & & & 0.000 \\
\hline 30-39 & $7.4(26)$ & $4.9(9)$ & & $5.7(57)$ & $4.4(19)$ & & $4.2(105)$ & $2.9(37)$ & \\
\hline $40-59$ & $58.6(207)$ & $53.8(98)$ & & $53.9(536)$ & $51.4(220)$ & & $52.5(1297)$ & $44.1(555)$ & \\
\hline $60+$ & $34(120)$ & $41.2(75)$ & & $40.4(402)$ & $44.2(189)$ & & $43.3(1069)$ & $53(667)$ & \\
\hline Education & & & 0.441 & & & 0.569 & & & 0.268 \\
\hline Primary/Secondary & $52.3(183)$ & $55.8(101)$ & & $59.9(591)$ & $61.6(261)$ & & $58.5(1432)$ & $60.4(751)$ & \\
\hline College/University education & $47.7(167)$ & $44.2(80)$ & & 40.1 (395) & $38.4(163)$ & & $41.5(1017)$ & $39.6(493)$ & \\
\hline Self-reported health & & & 0.984 & & & 0.962 & & & 0.439 \\
\hline Bad & $8.2(29)$ & $8.2(15)$ & & $10.3(102)$ & $10.4(44)$ & & 7.9 (194) & $6.8(85)$ & \\
\hline Neither good nor bad & $30.6(108)$ & $31.3(57)$ & & $33.8(333)$ & $33(140)$ & & 31 (759) & $32.1(400)$ & \\
\hline Good & $61.2(216)$ & $60.4(110)$ & & $55.9(551)$ & $56.6(240)$ & & $61.1(1499)$ & $61.1(763)$ & \\
\hline Marital status & & & 0.000 & & & 0.000 & & & 0.000 \\
\hline Single & $21.2(75)$ & $24.2(44)$ & & $18.8(187)$ & $24.1(103)$ & & $17.3(427)$ & $18.7(236)$ & \\
\hline Married/Registrated partner & $52.1(184)$ & $64.3(117)$ & & $51.9(516)$ & $62.6(268)$ & & $54.9(1356)$ & $64.3(810)$ & \\
\hline Widow/Widower & $9.3(33)$ & $1.6(3)$ & & $11.1(110)$ & $2.1(9)$ & & $10.3(254)$ & $4.2(53)$ & \\
\hline Divorced/Separated & $17.3(61)$ & $9.9(18)$ & & $18.3(182)$ & $11.2(48)$ & & $17.6(343)$ & $12.7(160)$ & \\
\hline Household income & & & 0.331 & & & 0.005 & & & 0.012 \\
\hline Low & $24.5(80)$ & $18.5(33)$ & & $26.6(243)$ & $18.4(75)$ & & $26(590)$ & $21.5(261)$ & \\
\hline Middel & $33(108)$ & $36(64)$ & & $34(310)$ & $36.4(148)$ & & $33.8(766)$ & $34.9(423)$ & \\
\hline High & 42.5 (139) & $45.5(81)$ & & $39.4(360)$ & $45.2(184)$ & & $40.2(913)$ & $43.6(528)$ & \\
\hline
\end{tabular}

${ }^{1}$ CAM 1 = Use of a CAM provider minimum 4 times last year.

${ }^{2} \mathrm{CAM} 2$ = Use of a CAM provider last year.

${ }^{3}$ CAM 3 = Use of a CAM provider, CAM OTC products or CAM techniques last year.

*Pearson Chi-Square test.

Comparison between female and male users of CAM.

of CAM vary [7]. Emphasizing comparability between studies, we have chosen to compare our study to a limited selection of other studies.

The most comparable study is the HUNT 3 study conducted in the county of Nord-Trøndelag, Central Norway in 2008. They found similar use at CAM level 2 as shown in the results from our study [9].

The previous Tromsø study (the $5^{\text {th }}$ Troms $\varnothing$ study), conducted in 2001/2002 reported lower use of CAM at level 2 compared to results from our group six years later $(13.5 \%$ in women and $4.8 \%$ in men without cancer or coronary heart disease) [10]. The higher use of CAM in this study might be due to a general increase in the use of CAM between 2002 and 2008 [6,23]. The preprepared list regarding the CAM providers might have improved the recall and clarified what to consider as CAM, and thereby increased the reported rate of CAM use [6].

The findings of $33.3 \%$ use at CAM level 3 are in accordance with a recent review that found $32.2 \%$ prevalence of use in the 16 studies included [2]. The findings from our study are also in accordance with findings from the UK and the US presented in another recent review [5]. However, our data report a lower prevalence of use than findings from Australia and South Korea [5]. The reason for this might be that South Korea has a stronger tradition of using traditional medicine, and that Australia is more influenced by traditional Eastern medicine due to geographical proximity.

The findings of a strong association between CAM use and being a young/middle age women with higher education and poor health, is in line with other studies [1,24-26]. That women in this study used CAM more often than men at all levels was also in line with previous research, showing that women tend to be more active in their own health promotion and are more concerned about health issues and caring compared to men [13,27]. Throughout the Western world women more often undertake health care visits [28-30], are more frequent utilizers of psychological support groups [31,32] and of health advice on the Internet [33], and the typical reader of a selfhelp book is a woman. The presence of a gender bias in 
Table 4 Socio demographic characteristics of female users and nonusers of CAM

\begin{tabular}{|c|c|c|c|c|c|c|c|c|c|}
\hline & & CAM $1^{1}$ & & & CAM $2^{2}$ & & & $\mathrm{CAMB}^{3}$ & \\
\hline & Non-users & & & Non-users & & & Non-users & Us & \\
\hline & $\%(n)$ & $\%(n)$ & p-value* & $\%(n)$ & $\%(n)$ & p-value* & $\%(n)$ & $\%(n)$ & p-value \\
\hline Age & & & 0.000 & & & 0.000 & & & 0.000 \\
\hline $30-39$ & $90(234)$ & $10(26)$ & & $78.2(205)$ & $21.8(57)$ & & $60.7(162)$ & $39.3(105)$ & \\
\hline $40-59$ & $92.4(2534)$ & $7.6(207)$ & & $80.8(2262)$ & $19.2(536)$ & & $54.9(1576)$ & $45.1(1297)$ & \\
\hline $60+$ & $95.3(2423)$ & $4.7(120)$ & & $84.8(2248)$ & $15.2(402)$ & & $60.9(1668)$ & $39.1(1069)$ & \\
\hline Education & & & 0.001 & & & 0.434 & & & 0.000 \\
\hline Primary/Secondary & $94.5(3140)$ & $5.5(183)$ & & $82.9(2858)$ & $17.1(591)$ & & $59.7(2124)$ & $40.3(1432)$ & \\
\hline College/University education & $92.3(1999)$ & $7.7(167)$ & & $82.1(1806)$ & 17.9 (395) & & $54.9(1238)$ & $45.1(1017)$ & \\
\hline Self-reported health & & & 0.012 & & & 0.000 & & & 0.000 \\
\hline Bad & $90.2(266)$ & $9.8(29)$ & & $67.8(215)$ & $32.2(102)$ & & $42.8(145)$ & $57.2(194)$ & \\
\hline Neither good nor bad & $92.9(1413)$ & $7.1(108)$ & & $78.9(1244)$ & $21.1(333)$ & & $53.4(870)$ & $46.6(759)$ & \\
\hline Good & $94.2(3478)$ & $5.8(216)$ & & $85.4(3226)$ & $14.6(551)$ & & $61.2(2367)$ & 38.8 (1499) & \\
\hline Marital status & & & 0.172 & & & 0.084 & & & 0.006 \\
\hline Single & $92.3(902)$ & $7.7(75)$ & & $81.2(808)$ & $18.8(187)$ & & $57.9(588)$ & $42.1(427)$ & \\
\hline Married/Registrated partner & $94(2877)$ & $6(184)$ & & $83.5(2613)$ & $16.5(516)$ & & $57.9(1866)$ & $42.1(1356)$ & \\
\hline Widow & $94.7(587)$ & $5.3(33)$ & & $83.3(550)$ & $16.7(110)$ & & $63.1(435)$ & $36.9(254)$ & \\
\hline Divorced/Separated & $93.1(825)$ & $6.9(61)$ & & $80.3(744)$ & $19.7(182)$ & & $54.4(517)$ & $45.6(434)$ & \\
\hline Household & & & 0.711 & & & 0.510 & & & 0.101 \\
\hline Low & $94(1264)$ & $6(80)$ & & $82.7(1161)$ & $17.3(243)$ & & $59.3(861)$ & $40.7(590)$ & \\
\hline Middel & $93.5(1541)$ & $6.5(108)$ & & $81.7(1383)$ & $18.3(310)$ & & $55.7(963)$ & $44.3(766)$ & \\
\hline High & 93.6 (1959) & $6.6(139)$ & & $83.1(1771)$ & $16.9(360)$ & & $58.1(1266)$ & $41.9(913)$ & \\
\hline
\end{tabular}

${ }^{1}$ CAM $1=$ Use of a CAM provider minimum 4 times last year.

${ }^{2} \mathrm{CAM} 2=$ Use of a CAM provider last year.

${ }^{3}$ CAM 3 = Use of a CAM provider, CAM OTC products or CAM.

Techniques last year.

*Pearson Chi-Square test.

health care, which can lead to a neglect of women's health care needs [17], might also contribute to women turning away from conventional patterns of care towards CAM providers and products.

Recent in-depth studies among Norwegian women using CAM support the findings that the public healthcare system in Norway may be unable to meet all the needs of female patients. The results illustrate subjectively experienced barriers related to the communication, understanding, and treatment of illness. Women diagnosed with breast cancer and multiple sclerosis express unmet needs with regard to their individual health care goals. They strongly emphasize the importance of CAM as a health care system that enables them to take active part in decision-making processes and treatment and, thereby, contribute to positive health outcomes for themselves. They not only relate to scientific, medical knowledge but also to experience-based knowledge (e.g., bodily experiences) $[34,35]$ as an important basis for their treatment decisions. By the decision to use CAM, and even in some cases to delay or decline conventional treatment, female
CAM users differ from the expected patient behavior and challenge the rationality of medical advice which traditionally has been defined and provided by men $[34,35]$.

However, another reason for the higher use in women might be the fact that women generally utilize more health services than men $[13,36]$. Together with the potential implications gender bias in healthcare has for women [17], this would explain why generally more women feel the need to seek alternatives to conventional care.

Women's widespread use of CAM in Western countries has also been suggested as an expression of traditional gender roles and dominant discourses of femininity, as being "help-seeking" and adhering to the "patient role" is more in coherence with a traditional femininity than masculinity $[37,38]$. The lower use of CAM among men may be explained by the fact that men adapt to preconceptions about a masculine behavior with little room for showing weakness and a need for help and support [27], and potentially the fact that their health care needs are better met within the public health care [17]. Another explanation is 
Table 5 Socio demographic characteristics of male users and nonusers of CAM

\begin{tabular}{|c|c|c|c|c|c|c|c|c|c|}
\hline & \multicolumn{3}{|c|}{ CAM $1^{1}$} & \multicolumn{3}{|c|}{$\mathrm{CAM2}^{2}$} & \multicolumn{3}{|c|}{$\mathrm{CAMB}^{3}$} \\
\hline & \multirow{2}{*}{$\begin{array}{c}\text { Non-users } \\
\%(n)\end{array}$} & \multicolumn{2}{|c|}{ Users } & \multirow{2}{*}{$\begin{array}{c}\text { Non-users } \\
\%(n)\end{array}$} & \multicolumn{2}{|c|}{ Users } & \multirow{2}{*}{$\begin{array}{c}\text { Non-users } \\
\%(n)\end{array}$} & \multicolumn{2}{|c|}{ Users } \\
\hline & & $\%(n)$ & p-value* & & $\%(n)$ & p-value* & & $\%(n)$ & p-value* \\
\hline Age & & & 0.154 & & & 0.202 & & & 0.001 \\
\hline 30-39 & $95.3(181)$ & $4.7(9)$ & & $90(171)$ & $10(19)$ & & $80.5(153)$ & $19.5(37)$ & \\
\hline $40-59$ & $96(2365)$ & $4(98)$ & & $84.8(2272)$ & $8.8(220)$ & & 77.9 (1953) & $22.1(555)$ & \\
\hline $60+$ & $96.9(2370)$ & $3.1(75)$ & & $92.4(2295)$ & $7.6(189)$ & & $73.6(1862)$ & $26.4(667)$ & \\
\hline Education & & & 0.416 & & & 0.255 & & & 0.245 \\
\hline Primary/Secondary & $96.6(2864)$ & $3.4(101)$ & & $91.3(2755)$ & $8.7(261)$ & & $75.4(2300)$ & $24.6(751)$ & \\
\hline College/University education & $96.2(2004)$ & $3.8(80)$ & & $92.2(1937)$ & $7.8(163)$ & & $76.8(1631)$ & $23.2(493)$ & \\
\hline Self-reported health & & & 0.008 & & & 0.000 & & & 0.000 \\
\hline Bad & $93.2(204)$ & $6.8(15)$ & & 80.7 (184) & $19.3(44)$ & & $63.4(147)$ & $36.6(85)$ & \\
\hline Neither good nor bad & $95.9(1322)$ & $4.1(57)$ & & $90(1267)$ & $10(140)$ & & $72.1(1032)$ & $27.9(400)$ & \\
\hline Good & $96.8(3361)$ & $3.2(110)$ & & $93.1(3262)$ & $6.9(240)$ & & $78.4(2769)$ & $21.6(763)$ & \\
\hline Marital status & & & 0.240 & & & 0.074 & & & 0.023 \\
\hline Single & $95.6(950)$ & $4.4(44)$ & & $89.8(907)$ & $10.2(103)$ & & 76.7 (779) & $23.3(236)$ & \\
\hline Married/Registrated partner & 96.5 (3199) & $3.5(117)$ & & $92(3088)$ & $8(268)$ & & $76.2(2587)$ & $23.8(810)$ & \\
\hline Widower & $97.6(143)$ & $2.1(3)$ & & 93.9 (139) & $6.1(9)$ & & $65.6(101)$ & $34.4(53)$ & \\
\hline Divorced/Separated & $97.2(624)$ & $2.8(18)$ & & $92.6(604)$ & $7.4(48)$ & & $75.8(501)$ & $24.2(160)$ & \\
\hline Household income & & & 0.484 & & & 0.135 & & & 0.000 \\
\hline Low' & $96.2(835)$ & $3.8(33)$ & & 91.5 (809) & $8.5(75)$ & & $71.1(642)$ & $28.9(261)$ & \\
\hline Middel & 96 (1539) & $4(64)$ & & $90.9(1472)$ & $9.1(148)$ & & $74.2(1219)$ & $25.8(423)$ & \\
\hline High & $96.7(2375)$ & $3.3(81)$ & & $92.6(2297)$ & $7.4(184)$ & & $78.9(1969)$ & $21.1(528)$ & \\
\hline
\end{tabular}

${ }^{1}$ CAM $1=$ Use of a CAM provider minimum 4 times last year.

${ }^{2}$ CAM 2 = Use of a CAM provider last year.

${ }^{3}$ CAM 3 = Use of a CAM provider, CAM OTC products or CAM technuiques last year.

*Pearson Chi-Square test.

related to ideas about men perceiving their body and health as being more "mechanical" than women, and that they, therefore, are less attracted to CAM where wholeness, communication and personal relation are more pronounced than the detailed biological mechanism [38].

The higher education among women using CAM was expected to correlate with the younger age. Analyzes adjusted for age, however, still show significant associations related to education. Women with higher education might be more able to find relevant information about CAM and to afford such treatment use. It can be speculated, that the higher educational background of women with a university education leads to higher self-confidence especially since even in modern Norway, it is not entirely the rule that women and men have the same education, in particular not for all of the age groups in this sample. It is not unlikely that this higher self-esteem makes females less apt to accept terms and conditions of treatment that they do not feel entirely comfortable with.

The lack of income differences between the users and non-users of CAM is in line with several other studies [26]. Recent studies suggest that CAM no longer is a phenomenon restricted to unique segments enjoying high family income [39].

\section{Limitations}

Despite the large sample size, the response rate $(65.7 \%)$ could have influenced the generalizability of our findings as the non-responders differed from the responders concerning age and sex. Men in the oldest and youngest age groups and women in the oldest age group had the lowest response rate. However, the non-responders in these groups consist of only 391 responders. Therefore, even though these groups would have been expected to use CAM to a lesser degree, the number of non-responders in these groups is so low that the likelihood of substantially influencing the final results is small.

The generalizability was also influenced by the 1,878 respondents that were excluded from the study due to missing response to the CAM questions. Generally, nonresponse to a CAM question is more likely to mean no use leading to an overestimated use of CAM in the analysis [40]. A non-responder-analysis, however, where the non-responders to the CAM questions are assumed to 
not having used CAM, showed that the tendencies are the same, though the significant level varies slightly.

The 12-month recall period concerning the use of CAM, might result in inaccuracies regarding the report of use. However, this factor is equally distributed between men and women.

One of the three questions regarding CAM asked for the use of herbal or "natural medicine" without defining this further. This could constitute an over- or underreporting of such use depending on how each participant defined their use. Moreover, young and old participants, men and women, might define this in different ways.

Traditional healing and CAM therapies might have different prevalence and associations for use. Both are combined in the same question, which makes a differentiation between associations for CAM and traditional healing, difficult.

\section{Conclusion}

Findings from this study suggest that the prevalence and associations for use of CAM differ between men and women concerning several socio demographic variables (age, education and household income). Norwegian women use CAM significantly more often than men at all levels of the use of CAM. The study revealed a strong association between the use of CAM and being a young/middle aged women with higher education and poor health.

\section{Abbreviations \\ CAM: Complementary and Alternative Medicine; NAFKAM: National Research Center in Complementary and Alternative Medicine; OTC: Over the counter.}

\section{Competing interests}

The authors declare that they have no competing interests.

\section{Authors' contributions}

AEK conceived the study, performed the initial and final analyses and drafted the manuscript. TS, AS, FM and KH helped draft the manuscript and reviewed subsequent versions. All authors read and approved the final manuscript.

\section{Acknowledgements}

Results from a regional cohort study (The $6^{\text {th }}$ Troms $\varnothing$ study) in Norway.

\section{Author details}

${ }^{1}$ The National Research Center in Complementary and Alternative Medicine (NAFKAM), Department of Community Medicine, Faculty of Health Sciences, UiT The Arctic University of Norway, Tromsø, Norway. ${ }^{2}$ Department of Community Medicine, Faculty of Health Sciences, UiT The Arctic University of Norway, Tromsø, Norway. ${ }^{3}$ Department of Public Health and Clinical Medicine, Family Medicine, Umeå University, Umeå, Sweden.

Received: 18 June 2014 Accepted: 13 November 2014 Published: 3 December 2014

\section{References}

1. Hanssen B, Grimsgaard S, Launso L, Fønnebø V, Falkenberg T, Rasmussen NK: Use of complementary and alternative medicine in the Scandinavian countries. Scand J Prim Health Care 2005, 23(1):57-62.

2. Frass M, Strassl RP, Friehs H, Mullner M, Kundi M, Kaye AD: Use and acceptance of complementary and alternative medicine among the general population and medical personnel: a systematic review. The Ochsner J 2012, 12(1):45-56.
3. NAFKAM-undersøkelsen. 2012 [http://nifab.no/om_alternativ_behandling/ alternativ_behandling_i_norge/nafkam_undersoekelsen_2012]

4. Johannessen $\mathrm{H}$, Ostenfeld-Rosenthal A: Alternative treatment. Practice and facts. [Alternativ behandling. Praksis og fakta.]. København: Munksgaard; 2012

5. Harris PE, Cooper KL, Relton C, Thomas KJ: Prevalence of complementary and alternative medicine (CAM) use by the general population: a systematic review and update. Int J Clin Pract 2012, 66(10):924-939.

6. Kristoffersen AE, Norheim AJ, Fonnebo VM: Complementary and alternative medicine use among Norwegian cancer survivors: genderspecific prevalence and associations for use. Evid Based Complement Alternat Med 2013, 2013:318781.

7. Kristoffersen $A E$, Fønnebø VM, Norheim AJ: Use of complementary and alternative medicine among patients: classification criteria determine level of use. J Altern Complement Med 2008, 14(8):911-919.

8. Health - More People Choose CAM Helse - flere velger alternativt]. [https:// www.ssb.no/helse/artikler-og-publikasjoner/helse-flere-velger-alternativt]

9. Steinsbekk A, Rise MB, Johnsen R: Changes among male and female visitors to practitioners of complementary and alternative medicine in a large adult Norwegian population from 1997 to 2008 (The HUNT studies). BMC Complement Altern Med 2011, 11:61.

10. Kristoffersen AE, Norheim AJ, Fonnebo VM: Any difference? Use of a CAM provider among cancer patients, coronary heart disease (CHD) patients and individuals with no cancer/CHD. BMC Complement Altern Med 2012, 12(1):1.

11. Molassiotis A, Scott JA, Kearney N, Pud D, Magri M, Selvekerova S, Bruyns I, Fernadez-Ortega P, Panteli V, Margulies A, Gudmundsdottir G, Milovics L, Ozden G, Platin N, Patiraki E: Complementary and alternative medicine use in breast cancer patients in Europe. Support Care Cancer 2006, 14(3):260-267.

12. Bishop FL, Yardley L, Lewith GT: A systematic review of beliefs involved in the use of complementary and alternative medicine. J Health Psychol 2007, 12(6):851-867.

13. Lorber J: Gender and the Social Construction of IIIness. Thousand Oaks, Calif: Sage Publications; 1997.

14. Doyal L: Sex, gender, and health: the need for a new approach. BMJ 2001, 323(7320):1061-1063.

15. McLay JS, Stewart D, George J, Rore C, Heys SD: Complementary and alternative medicines use by Scottish women with breast cancer: what, why and the potential for drug interactions? Eur J Clin Pharmacol 2012, 68(5):811-819.

16. Council on Ethical and Judicial Affairs, Association AM: Gender disparities in clinical decision making. JAMA 1991, 266(4):559-562.

17. Hamberg K: Gender bias in medicine. Womens Health (Lond Engl) 2008, 4(3):237-243.

18. Hariz GM, Nakajima T, Limousin P, Foltynie T, Zrinzo L, Jahanshahi M, Hamberg K: Gender distribution of patients with Parkinson's disease treated with subthalamic deep brain stimulation; a review of the 2000-2009 literature. Parkinsonism Relat Disord 2011, 17(3):146-149.

19. Jacobsen BK, Eggen AE, Mathiesen EB, Wilsgaard T, Njolstad I: Cohort profile: the Tromso study. Int J Epidemiol 2011, 41(4):961-967.

20. Emaus A, Degerstrom J, Wilsgaard T, Hansen BH, Dieli-Conwright CM, Furberg AS, Pettersen SA, Andersen LB, Eggen AE, Bernstein L, Thune I: Does a variation in self-reported physical activity reflect variation in objectively measured physical activity, resting heart rate, and physical fitness? Results from the Tromso study. Scand J Public Health 2010, 38(5 Suppl):105-118

21. Kiil MA, Salamonsen A: Embodied health practices: The use of Traditional Healing and Conventional Medicine in a North Norwegian Community. Academic Journal of Interdisciplinary Studies 2013, Volume 2 (3). ISSN 22813993.s 483-488.s doi:10.5901/ajis.2013.v2n3p483.

22. WHO/EDM/TRM: General Guidelines for Methodologies on Research and Evaluation of Traditional Medicine. 2000. http://www.who.int/medicines/ areas/traditional/definitions/en/

23. Fønnebø $V$, Launsø $L$ : Use of alternative treatment in Norway [Bruk av alternativ behandling i Norge]. http://nifab.no/hva_er_alternativ_behandling/ tall_og_fakta/nifab_undersoekelsen_2007.

24. Barnes PM, Bloom B, Nahin RL: Complementary and alternative medicine use among adults and children: United States, 2007. Natl Health Stat Rep 2008, 12:1-23

25. Steinsbekk A, Adams J, Sibbritt D, Jacobsen G, Johnsen R: Sociodemographic characteristics and health perceptions among male and female visitors to CAM practitioners in a total population study. Forsch Komplementmed 2008, 15(3):146-151. 
26. Bishop FL, Lewith GT: Who uses CAM? A narrative review of demographic characteristics and health factors associated with CAM use. Evid Based Complement Alternat Med 2010, 7(1):11-28.

27. Courtenay WH: Constructions of masculinity and their influence on men's well-being: a theory of gender and health. Soc Sci Med 2000, 50(10):1385-1401.

28. Hansen AH, Halvorsen PA, Ringberg U, Forde $\mathrm{OH}$ : Socio-economic inequalities in health care utilisation in Norway: a population based cross-sectional survey. BMC Health Serv Res 2012, 12:336.

29. Vikum E, Krokstad S, Holst D, Westin S: Socioeconomic inequalities in dental services utilisation in a Norwegian county: the third NordTrondelag Health Survey. Scand J Public Health 2012, 40(7):648-655.

30. Blackwell DL, Lucas JW, Clarke TC: Summary health statistics for U.S. adults: national health interview survey, 2012. Vital Health Stat Series 10, Data from the National Health Survey 2012, 2014(260):1-171.

31. Berglund G, Bolund C, Gustafsson UL, Sjoden PO: Is the wish to participate in a cancer rehabilitation program an indicator of the need? Comparisons of participants and non-participants in a randomized study. Psychooncology 1997, 6(1):35-46.

32. Krizek C, Roberts C, Ragan R, Ferrara JJ, Lord B: Gender and cancer support group participation. Cancer Pract 1999, 7(2):86-92.

33. Umefjord G, Hamberg K, Malker H, Petersson G: The use of an internetbased ask the doctor service involving family physicians: evaluation by a web survey. Fam Pract 2006, 23(2):159-166.

34. Salamonsen A, Kruse T, Eriksen SH: Modes of embodiment in breast cancer patients using complementary and alternative medicine. Qual Health Res 2012, 22(11):1497-1512.

35. Salamonsen A, Launso L, Kruse TE, Eriksen SH: Understanding unexpected courses of multiple sclerosis among patients using complementary and alternative medicine: a travel from recipient to explorer. Int I Qual Stud Health Well-Being 2010, 5: doi:10.3402/qhw.v5i2.5032.

36. Bakketeig L, Bergsjø P, Dahl S, Gram T, Haugland S, Jacobsen B, Mfl: Kvinner lider - menn dør. Folkehelse i et kjønnsperspektiv. [Women suffer - men die. Public health from a gender perspective]. Oslo, Norway: Gyldendal Akademisk, Norway; 2007.

37. Christie VM: Den andre medisinen [The other medicine]. Oslo: Univeristetsforlaget, Norway; 1991.

38. Schei B, Bakketeig LS: Kvinner lider - menn dør: folkehelse i et kjønnsperspektiv. Oslo: Gyldendal akademisk; 2007.

39. Boon H, Westlake K, Stewart M, Gray R, Fleshner N, Gavin A, Brown JB, Goel V: Use of complementary/alternative medicine by men diagnosed with prostate cancer: prevalence and characteristics. Urology 2003, 62(5):849-853.

40. Kristoffersen AE, Fønnebø VM, Norheim AJ: Do cancer patients with a poor prognosis use complementary and alternative medicine more often than others? J Altern Complement Med 2009, 15(1):35-40.

doi:10.1186/1472-6882-14-463

Cite this article as: Kristoffersen et al:: Gender differences in prevalence and associations for use of CAM in a large population study. BMC

Complementary and Alternative Medicine 2014 14:463.

\section{Submit your next manuscript to BioMed Central and take full advantage of:}

- Convenient online submission

- Thorough peer review

- No space constraints or color figure charges

- Immediate publication on acceptance

- Inclusion in PubMed, CAS, Scopus and Google Scholar

- Research which is freely available for redistribution

Submit your manuscript at www.biomedcentral.com/submit
C Biomed Central 